\title{
Timing of the Onset of Acute Respiratory Distress Syndrome: A Population-Based Study
}

\author{
Giath Shari MD, Marija Kojicic MD, Guangxi Li MD, Rodrigo Cartin-Ceba MD, \\ Cesar Trillo Alvarez MD, Rahul Kashyap MBBS, Yue Dong MD, Jaise T Poulose MBBS, \\ Vitaly Herasevich MD, Javier A Cabello Garza MD, and Ognjen Gajic MD
}

\begin{abstract}
BACKGROUND: Many patients with acute lung injury (ALI) and acute respiratory distress syndrome (ARDS) have had recent healthcare interventions prior to developing ALI/ARDS. OBJECTIVE: To determine the timing of ALI/ARDS onset in relation to hospital admission and other healthcare interventions. METHODS: We conducted a population-based observational cohort study with a validated electronic surveillance tool, and identified patients with possible ALI/ARDS among critically ill adults at Mayo Clinic hospitals that provide critical care services for Olmsted County, Minnesota, in 2006. Trained investigators independently reviewed electronic medical records and confirmed the presence and timing of ALI/ARDS based on the American-European consensus definition. RESULTS: Of 124 episodes of ALI in 118 patients, only 5 did not fulfill the ARDS criteria. The syndrome developed a median 30 hours (IQR 10-82 h) after hospital admission in 79 patients $(67 \%)$. ARDS was present on admission in 39 patients $(33 \%)$, of whom 14 had recent hospitalization, 6 were transferred from nursing homes, and 3 had recent out-patient contact (1 antibiotic prescription, 1 surgical intervention, and 1 chemotherapy). Only 16 ARDS patients (14\%) did not have known recent contact with a healthcare system. Compared to ARDS on admission, hospital-acquired ARDS was more likely to occur in surgery patients (54\% vs $15 \%$, $P<.001$ ), and had longer adjusted hospital stay (mean difference $8.9 \mathrm{~d}, 95 \%$ CI $0.3-17.4, P=.04$ ). CONCLUSIONS: ARDS in the community most often develops either during hospitalization or in patients who recently had contact with a healthcare system. These findings have important implications for potential preventive strategies. Key words: acute respiratory distress syndrome; ARDS; healthcare; community; critical illness. [Respir Care 2011;56(5):576-582. (c) 2011 Daedalus Enterprises]
\end{abstract}

\section{Introduction}

Giath Shari MD, Guangxi Li MD, Rodrigo Cartin-Ceba MD, Cesar Trillo Alvarez MD, Rahul Kashyap MBBS, Yue Dong MD, Jaise T Poulose MBBS, Vitaly Herasevich MD, Javier A Cabello Garza MD, and Ognjen Gajic MD are affiliated with the Division of Pulmonary and Critical Care Medicine, Department of Internal Medicine, and with the Multidisciplinary Epidemiology and Translational Research in Intensive Care (METRIC), Mayo Clinic, Rochester, Minnesota. Marija Kojicic MD is affiliated with the Institute for Pulmonary Diseases of Vojvodina, Sremska Kamenica, Serbia.

This research was partly supported by the Mayo Foundation.

The authors have disclosed no conflicts of interest.

Correspondence: Ognjen Gajic MD, Division of Pulmonary and Critical Care Medicine, Department of Internal Medicine, Mayo Clinic, Rochester MN 55905. E-mail: gajic.ognjen@mayo.edu.

DOI: $10.4187 /$ respcare.00901
Acute lung injury (ALI) and its more severe form, acute respiratory distress syndrome (ARDS), are major health problems common in intensive care units (ICUs), with an estimated 190,600 new cases per year and an associated 74,500 deaths and 3.6 million hospital days. ${ }^{1}$ Despite prior

See the Related Editorial on Page 714

reported improvement in mortality ${ }^{2}$ and the discovery of more appropriate treatment strategies such as mechanical ventilation with low tidal volume ${ }^{3}$ and conservative fluid management, ${ }^{4}$ the mortality rate remains as high as $26 \%$ according to the most recent and optimistic estimates. ${ }^{5}$ Survivors frequently experience long-term consequences, 
including reduced lung function, ${ }^{6-8}$ musculoskeletal abnormalities, ${ }^{6,8}$ and cognitive, psychiatric, and emotional disturbances. ${ }^{9}$ Most efforts have been directed toward treatment, and little work has been done on ALI/ARDS prevention. Studies that have aimed to identify ALI/ARDS risk factors have almost exclusively observed patients after ICU admission, ${ }^{10}$ included patients referred from other institutions, and rarely addressed why some patients with risk factors develop ARDS while others do not. ${ }^{11-13}$ Determining whether ALI and ARDS are healthcare-associated syndromes could be the first step toward prevention. The timing of ALI/ARDS development in relationship to hospital admission and a previous healthcare contact has not been studied.

The fact that only Mayo Foundation Hospitals have the capabilities to provide full critical care services in Olmsted County, Minnesota, provided the opportunity to perform detailed population-based epidemiologic studies of critical care syndromes in the community. We systematically evaluated the timing of ALI/ARDS onset in relation to hospital admission and healthcare contacts. We hypothesized that most ALI/ARDS cases develop after contact with a healthcare system, so a window of opportunity exists for preventing this devastating condition.

\section{Methods}

In this population-based retrospective cohort study we reviewed electronic medical records of Olmsted County residents identified via electronic surveillance of ALI/ ARDS in the ICUs of 2 Mayo Clinic hospitals in Rochester, Minnesota, over a 1-year period (2006). Our institutional review board approved the study and waived the informed-consent requirement because this was a retrospective study. We excluded patients who denied authorization to use their medical records for research.

\section{Computerized System for Identifying ALI/ARDS}

Patients with ALI/ARDS were identified with an electronic alert system (the "ALI Sniffer") that uses a structured-query-language (SQL) integrative database (the "ICU mart") at the Mayo Foundation Hospitals. The data are accumulated within 1 hour of entry into the electronic medical record system, and an automatic alert is created if the patient has the combination of qualifying $\mathrm{P}_{\mathrm{aO}_{2}} / \mathrm{F}_{\mathrm{IO}_{2}}$ (measured from an arterial blood sample) and qualifying chest radiograph report (trigger terms include "bilateral infiltrate" and "edema"). The ALI Sniffer system has been validated in previous studies. ${ }^{14,15}$ The investigators who reviewed the medical records underwent a structured ALI/ ARDS tutorial prior to reviewing the records. Each patient record was classified as either ALI/ARDS, cardiogenic pulmonary edema, both ALI/ARDS and cardiogenic pul- monary edema, or other. Classification disagreements were resolved via consensus.

\section{Definitions}

ALI and ARDS were identified according to the American-European Consensus Conference definition: acute hypoxemia $\left(\mathrm{P}_{\mathrm{aO}} / \mathrm{F}_{\mathrm{IO}_{2}}<300 \mathrm{~mm} \mathrm{Hg}\right.$ for ALI, and $<200 \mathrm{~mm} \mathrm{Hg}$ for ARDS), bilateral pulmonary infiltrates, and no evidence of elevated left atrial pressure as a cause of the acute decline. Nine-digit ZIP codes confirmed Olmsted County residency.

We defined a healthcare system contact as: recent hospitalization (within 3 months of this most recent admission); a transfer from a nursing home; seen as an out-patient within one week of this most recent admission; currently receiving chemotherapy; recently received any blood product; or recently underwent an out-patient surgery.

The ALI/ARDS onset was taken as the time at which either or both criteria $\left(\mathrm{P}_{\mathrm{aO}_{2}} / \mathrm{F}_{\mathrm{IO}_{2}}\right.$ and bilateral infiltrates) were met. $\mathrm{S}_{\mathrm{pO}_{2}}$ was recorded if there was a delay in arterial blood gas analysis, and we used $\mathrm{S}_{\mathrm{pO}_{2}} / \mathrm{F}_{\mathrm{IO}_{2}}$ as a proxy for $\mathrm{P}_{\mathrm{aO}_{2}} / \mathrm{F}_{\mathrm{IO}_{2}}$, with the recently published ${ }^{26}$ formula that $\mathrm{S}_{\mathrm{pO}_{2}} / \mathrm{F}_{\mathrm{IO}_{2}}<315 \mathrm{~mm} \mathrm{Hg}$ corresponds to $\mathrm{P}_{\mathrm{aO}_{2}} / \mathrm{F}_{\mathrm{IO}_{2}}$ $<300 \mathrm{~mm} \mathrm{Hg}$.

\section{Statistical Analysis}

Descriptive data were summarized as mean or median and number/percentage, as appropriate. We used the Wilcoxon rank-sum test, chi-square test, and the Fisher exact test to compare hospital-acquired versus communityacquired ARDS. We performed adjusted analyses with logistic regression, considering both clinical plausibility and statistical criteria (significance, co-linearity, and interaction) for selection of variables into the model. We used statistics software (JMP, SAS, Cary, North Carolina) for all data analysis. We included in the analysis only the first identified episode of ALI/ARDS in each patient.

\section{Results}

Among 1,707 adult ICU admissions from Olmsted County, the ALI Sniffer sent 418 alerts. We confirmed ARDS in 106 cases, cardiogenic pulmonary edema in 99 cases, both ARDS and cardiogenic pulmonary edema in 18 cases, and other etiologies (eg, atelectasis, pleural effusion, interstitial lung disease) in 196 cases. After excluding repeat ARDS events in patients who had multiple ARDS events, we included 118 cases in the analysis (Fig. 1). Inter-observer agreement was good (kappa $=0.83$ ).

Of the 39 patients (33\%) who had evidence of ARDS on hospital admission (community-acquired), 14 had recent hospitalization, 6 were nursing-home residents, and 3 


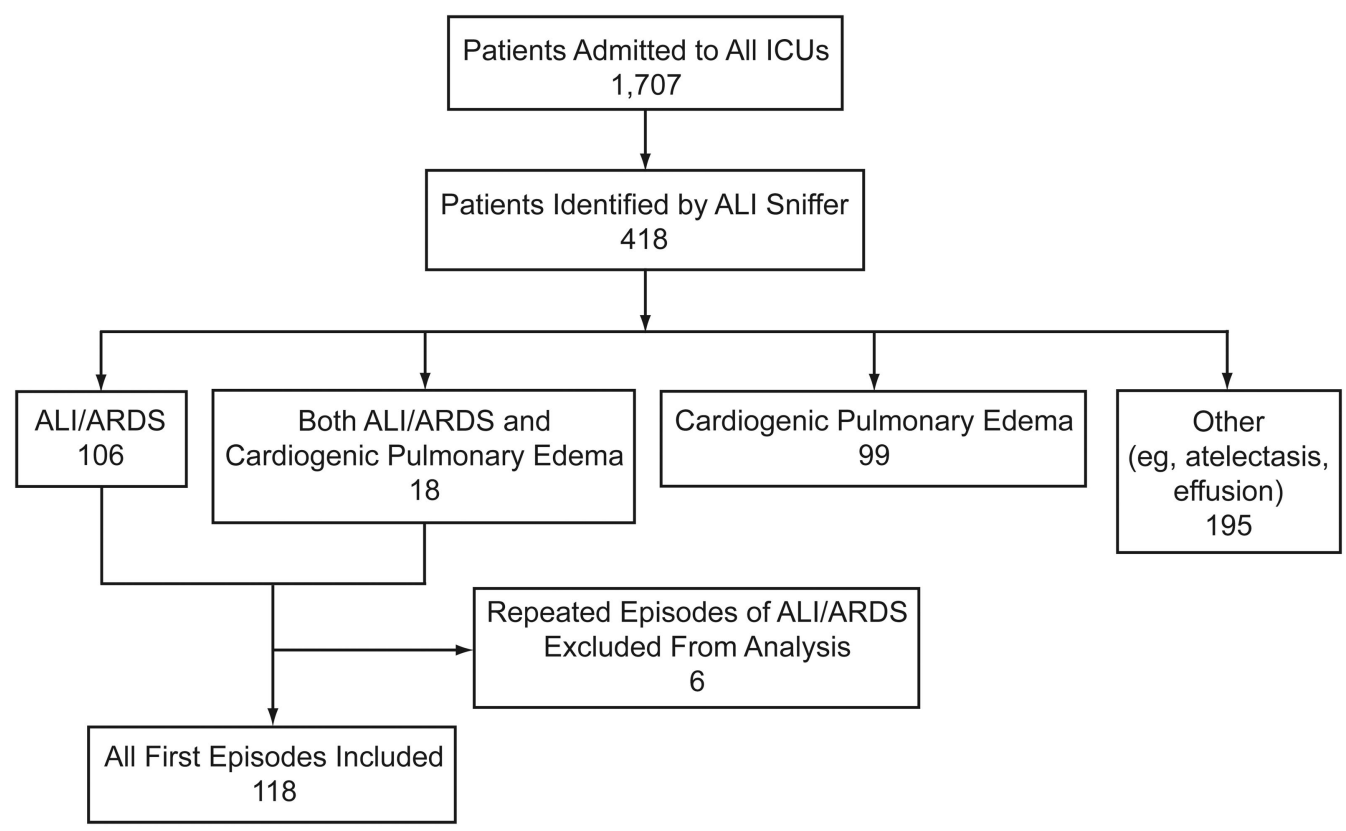

Fig. 1. Study outline.

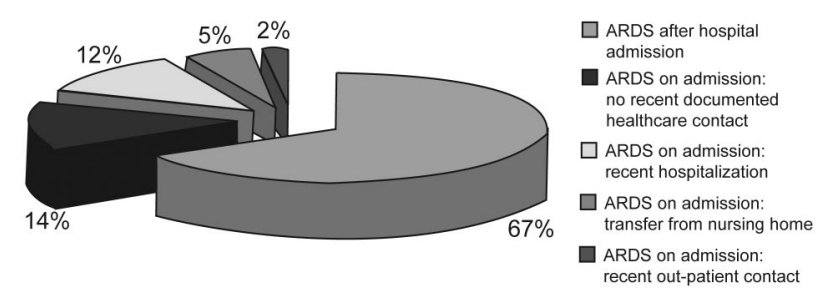

Fig. 2. Distribution of patients with acute respiratory distress syndrome (ARDS) in relation to recent healthcare contact.

had out-patient contacts with a healthcare system (1 had a physician's office visit, 1 had out-patient surgery, and 1 was receiving chemotherapy) (Fig. 2). Sixteen patients (14\%) had had no known recent healthcare contact prior to admission. Seventy-nine patients (67\%) had ARDS that developed after hospitalization (hospital-acquired). The median time to ARDS after hospital admission was 30 hours (IQR 10-82 h) (Fig. 3). Thirty-four patients (29\%) developed ARDS after ICU admission, and their median time to ARDS was 23 hours (IQR 13-69 h).

Table 1 outlines the characteristics of the patients with community-acquired and hospital-acquired ARDS. Hospital-acquired ARDS was more common in surgery patients. There were no statistically significant differences between the 2 groups in terms of demographics, severity of illness, alcohol abuse, malignancy, sepsis, trauma, or aspiration. The community-acquired-ARDS group had more profound hypoxemia $\left(\mathrm{P}_{\mathrm{aO}_{2}} / \mathrm{F}_{\mathrm{IO}_{2}} 64 \mathrm{~mm} \mathrm{Hg}\right.$ (IQR 49$98 \mathrm{~mm} \mathrm{Hg}$ ) vs $83 \mathrm{~mm} \mathrm{Hg}$ (IQR 60-130 $\mathrm{mm} \mathrm{Hg})(P=.02)$, whereas similar numbers of patients in the 2 groups had

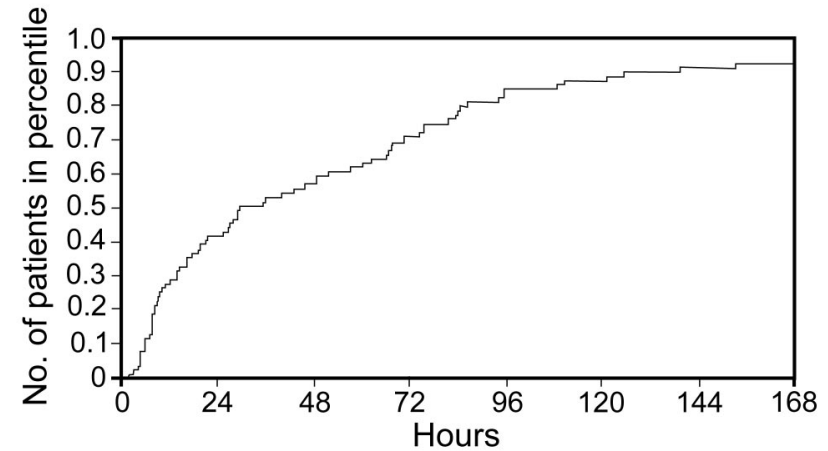

Fig. 3. Time to acute respiratory distress syndrome during the first week after hospital admission.

ALI that did not progress to ARDS (1 patient versus 4 patients, $P=.52$ ).

The community-acquired-ARDS group had shorter hospital stay and higher overall hospital mortality (Table 2). The results were similar among the hospital survivors. There were no statistically significant differences between the 2 groups in ICU stay, mechanical ventilation days, number of patients who required invasive mechanical ventilation, or number who required only noninvasive ventilation.

With multivariate logistic regression analysis to adjust for do-not-intubate/do-not-resuscitate (DNR/DNI) status, Acute Physiology and Chronic Health Evaluation (APACHE) III score, and surgery, the mortality difference in the hospitalacquired-ARDS group was not statistically significant (odds ratio $0.47,95 \% \mathrm{CI} 0.19-1.17, P=.10$ ), but hospital stay was significantly longer $(8.9 \mathrm{~d}, 95 \% \mathrm{CI} 0.3-17.4, P=.04)$. 
Timing of the Onset of Acute Respiratory Distress Syndrome

Table 1. Characteristics of Patients With Community-Acquired Versus Hospital-Acquired ARDS

\begin{tabular}{|c|c|c|c|}
\hline & $\begin{array}{c}\text { Community-Acquired } \\
\text { ARDS } \\
\end{array}$ & $\begin{array}{c}\text { Hospital-Acquired } \\
\text { ARDS } \\
\end{array}$ & $P$ \\
\hline \multicolumn{4}{|l|}{ Demographics } \\
\hline Patients, no. (\%) & $39(33)$ & $79(67)$ & \\
\hline Age, median (IQR), y & $74(58-81)$ & $67(53-77)$ & .12 \\
\hline Female, no. (\%) & $17(44)$ & $39(49)$ & .55 \\
\hline BMI, median (IQR), $\mathrm{kg} / \mathrm{m}^{2}$ & $26(23-31)$ & $27(23-30)$ & .66 \\
\hline DNR/DNI status & $5(13)$ & $3(4)$ & .07 \\
\hline \multicolumn{4}{|l|}{ Risk Factors and Comorbidities, no. (\%) } \\
\hline Surgery & $6(15)$ & $43(54)$ & $<.001$ \\
\hline Alcohol abuse & $6(15)$ & $17(22)$ & .43 \\
\hline Malignancy & $8(21)$ & $17(22)$ & .90 \\
\hline Pneumonia & $23(59)$ & $27(34)$ & .01 \\
\hline Sepsis & $17(44)$ & $29(37)$ & .47 \\
\hline Trauma & $3(8)$ & $6(8)$ & .98 \\
\hline Aspiration & $9(23)$ & $9(11)$ & .10 \\
\hline \multicolumn{4}{|l|}{ Severity of Illness } \\
\hline APACHE III & $78(64-106)$ & $72(57-89)$ & .10 \\
\hline Lowest $\mathrm{P}_{\mathrm{aO}_{2}} / \mathrm{F}_{\mathrm{IO}_{2}}$, median (IQR), mm Hg & $64(49-98)$ & $83(60-130)$ & .02 \\
\hline ALI only, no. $(\%)$ & $1(3)$ & $4(5)$ & .52 \\
\hline \multicolumn{4}{|c|}{$\begin{array}{l}\text { ARDS = acute respiratory distress syndrome } \\
\text { BMI = body mass index } \\
\text { DNR/DNI = do not resuscitate/do not intubate status at ARDS onset } \\
\text { APACHE = Acute Physiology and Chronic Health Evaluation } \\
\text { ALI = acute lung injury }\end{array}$} \\
\hline
\end{tabular}

Table 2. Outcomes of Patients With Community-Acquired Versus Hospital-Acquired ARDS

\begin{tabular}{|c|c|c|c|}
\hline & $\begin{array}{l}\text { Community- } \\
\text { Acquired ARDS }\end{array}$ & $\begin{array}{c}\text { Hospital- } \\
\text { Acquired ARDS }\end{array}$ & $P$ \\
\hline Intubation/mechanical ventilation, no. (\%) & $30(77)$ & $61(77)$ & .97 \\
\hline Noninvasive ventilation only, no. (\%) & $5(13)$ & $4(5)$ & .13 \\
\hline Mechanical ventilation days, median (IQR), d & $3.7(1.0-7.4)$ & $3.6(1.0-7.1)$ & .87 \\
\hline Hospital mortality, no. (\%) & $22(56)$ & $22(28)$ & .002 \\
\hline ICU stay, median (IQR), d & $3.3(0.7-7.5)$ & $4.0(1.9-8.2)$ & .08 \\
\hline Hospital stay, median (IQR), d & $7.0(1.8-14.8)$ & $13.9(8.2-25.1)$ & $<.001$ \\
\hline ICU-free days, ${ }^{*}$ median (IQR), d & $0(0-23)$ & $21(0$ to 25$)$ & .02 \\
\hline Hospital-free days, $\uparrow$ median (IQR), d & $0(0-46)$ & $39(0-49)$ & .10 \\
\hline \multicolumn{4}{|l|}{$\begin{array}{l}\text { * To day } 28 \text { for ICU-free days. } \\
\dagger \text { To day } 60 \text { for hospital-free days. } \\
\text { ARDS = acute respiratory distress syndrome } \\
\text { ICU = intensive care unit }\end{array}$} \\
\hline
\end{tabular}

Since some of the community-acquired ARDS may be misclassified because of late ARDS recognition, we performed a post-hoc sensitivity analysis based on the timing of ALI/ARDS onset $>24$ hours to define hospitalacquired ARDS (Tables 3 and 4). Between the patients whose ARDS onset was within 24 hours of admission and those whose ARDS onset was more than 24 hours after admission, there were significant differences only in APACHE III score, lowest $\mathrm{P}_{\mathrm{aO}} / \mathrm{F}_{\mathrm{IO}_{2}}$, and hospital stay. In multivariate analysis adjusting for pneumonia, DNR/DNI status, surgery, and APACHE III score, the mortality difference between the 2 groups remained nonsignificant (odds ratio $1.77,95 \% \mathrm{CI} 0.74-4.33, P=.20$ ), but hospital stay was still significantly longer $(8.0 \mathrm{~d}, 95 \%$ CI $0.3-15.8 \mathrm{~d}$, $P=.04)$.

\section{Discussion}

This population-based observational cohort study reveals new and interesting facts regarding the timing of ARDS 
Table 3. Characteristics of Patients With ARDS Onset Before Versus After 24 Hours of Hospital Admission

\begin{tabular}{|c|c|c|c|}
\hline & $\begin{array}{c}\text { ARDS Onset } \leq 24 \text { Hours } \\
\text { After Admission }\end{array}$ & $\begin{array}{c}\text { ARDS Onset }>24 \text { Hours } \\
\text { After Admission }\end{array}$ & $P$ \\
\hline \multicolumn{4}{|l|}{ Demographics } \\
\hline Patients, no. (\%) & $71(60)$ & $47(40)$ & \\
\hline Age, median (IQR), y & $72(54-80)$ & $67(53-77)$ & .58 \\
\hline Female, no. (\%) & $31(44)$ & $25(53)$ & .31 \\
\hline BMI, median (IQR), $\mathrm{kg} / \mathrm{m}^{2}$ & $25(23-30)$ & $27(24-33)$ & .66 \\
\hline DNR/DNI status & $6(8)$ & $2(4)$ & .37 \\
\hline \multicolumn{4}{|l|}{ Risk Factors and Comorbidities, no. (\%) } \\
\hline Surgery & $25(35)$ & $24(42)$ & .09 \\
\hline Alcohol abuse & $15(21)$ & $8(17)$ & .58 \\
\hline Malignancy & $13(18)$ & $12(25)$ & .35 \\
\hline Pneumonia & $31(44)$ & $19(41)$ & .73 \\
\hline Sepsis & $29(41)$ & $17(36)$ & .61 \\
\hline Trauma & $4(6)$ & $5(11)$ & .32 \\
\hline Aspiration & $12(17)$ & $6(13)$ & .54 \\
\hline \multicolumn{4}{|l|}{ Severity of Illness } \\
\hline APACHE III & $80(63-99)$ & $68(53-81)$ & .03 \\
\hline Lowest $\mathrm{P}_{\mathrm{aO}_{2}} / \mathrm{F}_{\mathrm{IO}_{2}}$, median (IQR), mm Hg & $64(49-98)$ & $83(60-130)$ & .03 \\
\hline ALI only & $1(4)$ & $4(8)$ & .06 \\
\hline \multicolumn{4}{|c|}{$\begin{array}{l}\text { ARDS = acute respiratory distress syndrome } \\
\text { BMI = body mass index } \\
\text { DNR/DNI = do not resuscitate/do not intubate status at ARDS onset } \\
\text { APACHE = Acute Physiology and Chronic Health Evaluation } \\
\text { ALI = acute lung injury }\end{array}$} \\
\hline
\end{tabular}

Table 4. Outcomes of Patients With Community-Acquired Versus Hospital-Acquired ARDS

\begin{tabular}{|c|c|c|c|}
\hline & $\begin{array}{c}\text { ARDS Onset } \leq 24 \text { Hours } \\
\text { After Admission }\end{array}$ & $\begin{array}{c}\text { ARDS Onset }>24 \text { Hours } \\
\text { After Admission }\end{array}$ & $P$ \\
\hline Intubation/mechanical ventilation, no. (\%) & $54(76)$ & $37(79)$ & .74 \\
\hline Noninvasive ventilation only, no. (\%) & $6(8)$ & $3(6)$ & .67 \\
\hline Mechanical ventilation days, median (IQR), d & $3.8(1.2-7.4)$ & $4.0(1.3-8.8)$ & .57 \\
\hline Hospital mortality, no. (\%) & $26(37)$ & $18(38)$ & .85 \\
\hline ICU stay, median (IQR), d & $4.0(1.2-7.9)$ & $4.0(1.9-8.1)$ & .91 \\
\hline Hospital stay, median (IQR), d & $10.0(3.4-16.8)$ & $15.0(9.9-24.6)$ & $<.006$ \\
\hline ICU-free days, ${ }^{*}$ median (IQR), d & $0(0-25)$ & $0(0-23)$ & .66 \\
\hline Hospital-free days, $\uparrow$ median (IQR), d & $0(0-52)$ & $0(0-47)$ & .45 \\
\hline $\begin{array}{l}\text { * To day } 28 \text { for ICU-free days. } \\
\dagger \text { To day } 60 \text { for hospital-free days. } \\
\text { ARDS = acute respiratory distress syndrome } \\
\text { ICU = intensive care unit }\end{array}$ & & & \\
\hline
\end{tabular}

and its relation to healthcare-system exposure. Our findings suggest that ARDS is mainly a healthcare-related syndrome, as only $14 \%$ of our population did not have known healthcare contact prior to ALI/ARDS onset. Our study also shows a substantial time gap between hospital admission and ALI/ARDS onset, which suggests a potential window for future ARDS mechanistic studies and clinical trials of preventive strategies.

The principal barrier toward better understanding of the clinical pathogenesis of ALI/ARDS and the design and conduct of ALI/ARDS preventive strategies is the fact that previous clinical studies focused almost exclusively on patients admitted to the ICU.10-12,17-24 Our systematic approach supplements prior studies that suggested a substantial time gap between the initial development of ARDS risk factors during hospitalization, or even the initiation of mechanical ventilation in critically ill patients admitted to the ICU, and the development of ARDS.12,25,26

We believe that understanding the time course of ALI/ ARDS is the first step toward prevention. Subsequent steps 
can include developing accurate prediction models to identify patients at high risk of ALI/ARDS, and applying preventive or therapeutic strategies, analogous to other several important critical care syndromes, such as stress ulcer bleed, ventilator-associated pneumonia, central venous catheter infection, and venous thromboembolism. Our preliminary studies suggest the plausibility of this approach. Observing the evolution of ARDS in rat lung exposed to injurious ventilation ${ }^{27}$ prompted the clinical investigation of the relationship between initial ventilator settings and the development of ARDS in patients who did not have ARDS at the outset. Intriguing preliminary results suggested that the processes of care, namely, high-tidalvolume mechanical ventilation and liberal transfusion, were more important ARDS risk factors than the initial severity of illness. ${ }^{26}$ Both ventilator settings and transfusion factors were associated with the development of ARDS, in a dosedependent manner. ${ }^{26,28}$ Indeed, a quality-improvement intervention aimed at decreasing ventilator tidal volume and liberal transfusion decreased harmful exposures and was associated with a reduced incidence of ARDS in mechanically ventilated patients without ALI at the outset. ${ }^{29}$

Our study found that patients with community-acquired ARDS were more likely to be medical patients (85\%) with pneumonia (59\%), whereas those who developed ARDS after hospital admission were more likely to be surgery patients (54\%). TenHoor et al found a proportional mortality ratio (death from ALI vs other causes) of 11.8 (95\% CI 3.8-36.0) with ICD-9 code E870-879.9, "surgical or medical misadventures" such as accidental perforation during medical or surgical care, foreign objects left in body, failure of sterile precautions during a procedure, failure in dosage, contamination of blood or other fluids, and related iatrogenic exposures. ${ }^{30}$

Prior data suggest that ARDS due to "pulmonary" etiologies had worse oxygenation than ARDS due to "extrapulmonary" causes, ${ }^{31,32}$ which may explain the $\mathrm{P}_{\mathrm{aO}_{2}} / \mathrm{F}_{\mathrm{IO}_{2}}$ difference between the 2 groups in our study, given the fact that the community-acquired ARDS had worse oxygenation and more pneumonia. However, other facts related to possible delayed recognition and treatment of ARDS in the community-acquired group offer an alternative explanation. Although the hospital-acquired-ARDS group had lower unadjusted hospital mortality, the difference was not statistically significant after adjusting for baseline differences, which may be due to the small sample size; however, prior studies did not find a mortality difference when comparing pulmonary (more common in the community-acquired-ARDS group) versus extrapulmonary ARDS etiologies. ${ }^{33}$

Another interesting finding was the difference in hospital stay between the 2 groups. A possible explanation is that ARDS in the hospital developed due to complications of healthcare delivery, which increased stay. Another possibility is that the community-acquired-ARDS group had a higher DNR/DNI rate and more severe pulmonary dysfunction, so they were more likely to die faster than the other group.

Among the strengths of our study was our use of a population-based sample and hospital-wide electronic medical records, allowing for more precise estimation of the time of ARDS onset than would be otherwise possible. On the other hand, our study was retrospective and in a single institution, so the results may not apply to other centers and populations. The timing of ARDS was determined by the first recorded time at which the patient met the American-European Consensus Conference criteria for ALI/ARDS, which might have been after the actual time of ARDS onset, due to the delay in obtaining diagnostic studies such as arterial blood gases and chest imaging. However, our use of $\mathrm{S}_{\mathrm{pO}_{2}} / \mathrm{F}_{\mathrm{IO}_{2}}$, when recorded, diminished that limitation.

The evidence of left atrial hypertension was based on available hemodynamic monitoring (central venous pressure) and echocardiography, but we did not collect detailed data on those variables, and pulmonary artery catheter was infrequently used. In addition, the threshold we chose for defining community-acquired ARDS is arbitrary, and it is certainly possible that some patients were already on the way to developing full-blown ALI at the time of enrollment. Therefore, in this study "ARDS onset" refers to "ARDS recognition," and these do not necessarily occur at the same time. On the other hand, most ALI/ARDS etiologies, such as septic shock and transfusion-related lung injury, take no more than 6-12 hours from the initial insult. 34,35 Similarly, electivesurgery patients clearly do not have ARDS on admission. Our post-hoc sensitivity analysis to distinguish patients who developed ALI/ARDS before versus after $>24$ hours found no significant differences in the main outcomes.

\section{Conclusions}

ALI/ARDS is rarely present on admission and without a recent contact with the healthcare system; rather, it develops after admission. The time gap between hospital admission and ARDS onset highlights the need to identify at-risk patients early, by developing accurate prediction models. Then efforts should be directed toward creating effective preventive strategies.

\section{REFERENCES}

1. Rubenfeld GD, Caldwell E, Peabody E, Weaver J, Martin DP, Neff $\mathrm{M}$, et al. Incidence and outcomes of acute lung injury. N Engl J Med 2005;353(16):1685-1693.

2. Milberg JA, Davis DR, Steinberg KP, Hudson LD. Improved survival of patients with acute respiratory distress syndrome (ARDS): 1983-1993. JAMA 1995;273(4):306-309.

3. The Acute Respiratory Distress Syndrome Network. Ventilation with lower tidal volumes as compared with traditional tidal volumes for acute lung injury and the acute respiratory distress syndrome. N Engl J Med 2000;342(18):1301-1308. 
4. Wiedemann HP, Wheeler AP, Bernard GR, Thompson BT, Hayden D, deBoisblanc B, et al. Comparison of two fluid-management strategies in acute lung injury. N Engl J Med 2006;354(24):2564-2575.

5. Erickson SE, Martin GS, Davis JL, Matthay MA, Eisner MD. Recent trends in acute lung injury mortality: 1996-2005. Crit Care Med 2009;37(5):1574-1579.

6. Cheung AM, Tansey CM, Tomlinson G, Diaz-Granados N, Matte A, Barr A, et al. Two-year outcomes, health care use, and costs of survivors of acute respiratory distress syndrome. Am J Respir Crit Care Med 2006;174(5):538-544.

7. Orme J Jr, Romney JS, Hopkins RO, Pope D, Chan KJ, Thomsen G, et al. Pulmonary function and health-related quality of life in survivors of acute respiratory distress syndrome. Am J Respir Crit Care Med 2003;167(5):690-694.

8. Herridge MS, Cheung AM, Tansey CM, Matte-Martyn A, Diaz-Granados N, Al-Saidi F, et al. One-year outcomes in survivors of the acute respiratory distress syndrome. N Engl J Med 2003;348(8):683-693.

9. Hopkins RO, Weaver LK, Collingridge D, Parkinson RB, Chan KJ, Orme JF Jr. Two-year cognitive, emotional, and quality-of-life outcomes in acute respiratory distress syndrome. Am J Respir Crit Care Med 2005;171(4):340-347.

10. Hudson LD, Milberg JA, Anardi D, Maunder RJ. Clinical risks for development of the acute respiratory distress syndrome. Am J Respir Crit Care Med 1995;151(2 Pt 1):293-301.

11. Fowler AA, Hamman RF, Good JT, Benson KN, Baird M, Eberle DJ, et al. Adult respiratory distress syndrome: risk with common predispositions. Ann Intern Med 1983;98(5 Pt 1):593-597.

12. Pepe PE, Potkin RT, Reus DH, Hudson LD, Carrico CJ. Clinical predictors of the adult respiratory distress syndrome. Am J Surg 1982;144(1):124-130.

13. Ferguson ND, Frutos-Vivar F, Esteban A, Gordo F, Honrubia T, Penuelas $\mathrm{O}$, et al. Clinical risk conditions for acute lung injury in the intensive care unit and hospital ward: a prospective observational study. Crit Care 2007;11(5):R96.

14. Herasevich V, Yilmaz M, Khan H, Chute CG, Gajic O. Rule base system for identification of patients with specific critical care syndromes: the "sniffer" for acute lung injury. AMIA Annu Symp Proc 2007;972.

15. Herasevich V, Yilmaz M, Khan H, Hubmayr RD, Gajic O. Validation of an electronic surveillance system for acute lung injury. Intensive Care Med 2009;35(6):1018-1023.

16. Rice TW, Wheeler AP, Bernard GR, Hayden DL, Schoenfeld DA, Ware LB. Comparison of the $\mathrm{S}_{\mathrm{pO} 2} / \mathrm{F}_{\mathrm{IO} 2}$ ratio and the $\mathrm{P}_{\mathrm{aO} 2} / \mathrm{F}_{\mathrm{IO} 2}$ ratio in patients with acute lung injury or acute respiratory distress syndrome. Chest 2007;132(2):410-417.

17. Gong MN, Thompson BT, Williams P, Pothier L, Boyce PD, Christiani DC. Clinical predictors of and mortality in acute respiratory distress syndrome: potential role of red cell transfusion. Crit Care Med 2005;33(6):1191-1198.

18. Khan H, Belsher J, Yilmaz M, Afessa B, Winters JL, Moore SB, et al. Fresh-frozen plasma and platelet transfusions are associated with development of acute lung injury in critically ill medical patients. Chest 2007;131(5):1308-1314.

19. Irish Critical Care Trials Group. Acute lung injury and the acute respiratory distress syndrome in Ireland: a prospective audit of epidemiology and management. Crit Care 2008;12(1):R30.
20. Silverboard H, Aisiku I, Martin GS, Adams M, Rozycki G, Moss M. The role of acute blood transfusion in the development of acute respiratory distress syndrome in patients with severe trauma. J Trauma 2005;59(3):717-723.

21. Mangialardi RJ, Martin GS, Bernard GR, Wheeler AP, Christman BW, Dupont WD, et al. Hypoproteinemia predicts acute respiratory distress syndrome development, weight gain, and death in patients with sepsis. Ibuprofen in Sepsis Study Group. Crit Care Med 2000; 28(9):3137-3145.

22. Moss M, Guidot DM, Steinberg KP, Duhon GF, Treece P, Wolken R, et al. Diabetic patients have a decreased incidence of acute respiratory distress syndrome. Crit Care Med 2000;28(7):2187-2192.

23. Eberhard LW, Morabito DJ, Matthay MA, Mackersie RC, Campbell AR, Marks JD, et al. Initial severity of metabolic acidosis predicts the development of acute lung injury in severely traumatized patients. Crit Care Med 2000;28(1):125-131.

24. Moss M, Burnham EL. Chronic alcohol abuse, acute respiratory distress syndrome, and multiple organ dysfunction. Crit Care Med 2003;31(4 Suppl):S207-S212.

25. Jia X, Malhotra A, Saeed M, Mark RG, Talmor D. Risk factors for ARDS in patients receiving mechanical ventilation for $48 \mathrm{~h}$. Chest 2008;133(4):853-861.

26. Gajic O, Dara SI, Mendez JL, Adesanya AO, Festic E, Caples SM, et al. Ventilator-associated lung injury in patients without acute lung injury at the onset of mechanical ventilation. Crit Care Med 2004; 32(9):1817-1824.

27. Gajic O, Lee J, Doerr CH, Berrios JC, Myers JL, Hubmayr RD. Ventilator-induced cell wounding and repair in the intact lung. Am J Respir Crit Care Med 2003;167(8):1057-1063.

28. Gajic O, Rana R, Mendez JL, Rickman OB, Lymp JF, Hubmayr RD, Moore SB. Acute lung injury after blood transfusion in mechanically ventilated patients. Transfusion 2004;44(10):1468-1474.

29. Yilmaz M, Keegan MT, Iscimen R, Afessa B, Buck CF, Hubmayr $\mathrm{RD}$, Gajic O. Toward the prevention of acute lung injury: protocolguided limitation of large tidal volume ventilation and inappropriate transfusion. Crit Care Med 2007;35(7):1660-1666.

30. TenHoor T, Mannino DM, Moss M. Risk factors for ARDS in the United States: analysis of the 1993 National Mortality Followback Study. Chest 2001;119(4):1179-1184.

31. Gattinoni L, Pelosi P, Suter PM, Pedoto A, Vercesi P, Lissoni A. Acute respiratory distress syndrome caused by pulmonary and extrapulmonary disease: different syndromes? Am J Respir Crit Care Med 1998;158(1):3-11.

32. Tugrul S, Akinci O, Ozcan PE, Ince S, Esen F, Telci L, et al. Effects of sustained inflation and postinflation positive end-expiratory pressure in acute respiratory distress syndrome: focusing on pulmonary and extrapulmonary forms. Crit Care Med 2003;31(3):738-744.

33. Agarwal R, Srinivas R, Nath A, Jindal SK. Is the mortality higher in the pulmonary vs the extrapulmonary ARDS? A meta analysis. Chest 2008;133(6): 1463-1473.

34. Greer R. The temporal evolution of acute respiratory distress syndrome following shock. Eur J Anaesthesio 2010;27(3):226-232.

35. Toy P, Popovsky MA, Abraham E, Ambruso DR, Holness LG, Kopko PM, McFarland JG, Nathens AB, Silliman CC, Stroncek D. Transfusion-related acute lung injury: definition and review. Crit Care Med 2005;33(4):721-726.

This article is approved for Continuing Respiratory Care Education credit. For information and to obtain your CRCE

(free to AARC members) visit www.RCJournal.com

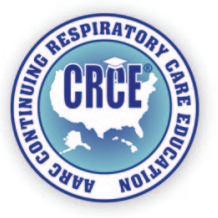

